\title{
BMJ Open Systematic review of systematic reviews for effectiveness of internal fixation for flail chest and rib fractures in adults
}

\author{
Helen MA Ingoe, ${ }^{\oplus 1,2}$ Elizabeth Coleman, ${ }^{1}$ William Eardley, ${ }^{1,2}$ Amar Rangan, ${ }^{\oplus 1,2,3}$ \\ Catherine Hewitt, ${ }^{1}$ Catriona McDaid ${ }^{\oplus 1}$
}

To cite: Ingoe HMA, Coleman E, Eardley W, et al. Systematic review of systematic reviews for effectiveness of internal fixation for flail chest and rib fractures in adults. BMJ Open 2019;9:e023444. doi:10.1136/ bmjopen-2018-023444

- Prepublication history and additional material for this paper are available online. To view these files, please visit the journal online (http://dx.doi. org/10.1136/bmjopen-2018023444).

Received 10 April 2018

Revised 2 December 2018

Accepted 11 February 2019

Check for updates

(C) Author(s) (or their employer(s)) 2019. Re-use permitted under CC BY-NC. No commercial re-use. See rights and permissions. Published by BMJ.

${ }^{1}$ York Trials Unit, Health Sciences, University of York, York, UK

${ }^{2}$ Trauma and Orthopaedics, The James Cook University Hospital, Middlesbrough, UK

${ }^{3}$ Nuffield Department of Orthopaedics Rheumatology and Musculoskeletal Sciences, University of Oxford, Oxford, UK

Correspondence to

Dr Helen MA Ingoe;

helen.ingoe@york.ac.uk

\section{ABSTRACT}

Objectives Multiple systematic reviews have reported on the impact of rib fracture fixation in the presence of flail chest and multiple rib fractures, however this practice remains controversial. Our aim is to synthesise the effectiveness of surgical rib fracture fixation as evidenced by systematic reviews.

Design A systematic search identified systematic reviews comparing effectiveness of rib fracture fixation with non-operative management of adults with flail chest or unifocal non-flail rib fractures. MEDLINE, EMBASE, Cochrane Database of Systematic Reviews and Science Citation Index were last searched 17 March 2017. Risk of bias was assessed using the Risk Of Bias In Systematic reviews (ROBIS) tool. The primary outcome was duration of mechanical ventilation.

Results Twelve systematic reviews were included, consisting of 3 unique randomised controlled trials and 19 non-randomised studies. Length of mechanical ventilation was shorter in the fixation group compared with the nonoperative group in flail chest; pooled estimates ranged from -4.52 days, $95 \% \mathrm{Cl}(-5.54$ to -3.5$)$ to -7.5 days, $95 \% \mathrm{Cl}(-9.9$ to -5.5$)$. Pneumonia, length of hospital and intensive care unit stay all showed a statistically significant improvement in favour of fixation for flail chest; however, all outcomes in favour of fixation had substantial heterogeneity. There was no statistically significant difference between groups in mortality. Two systematic reviews included one non-randomised studies of unifocal non-flail rib fracture population; due to limited evidence the benefits with surgery are uncertain.

Conclusions Synthesis of the reviews has shown some potential improvement in patient outcomes with flail chest after fixation. For future review updates, meta-analysis for effectiveness may need to take into account indications and timing of surgery as a subgroup analysis to address clinical heterogeneity between primary studies. Further robust evidence is required before conclusions can be drawn of the effectiveness of surgical fixation for flail chest and in particular, unifocal non-flail rib fractures.

PROSPERO registration number CRD42016053494.

\section{INTRODUCTION}

Multiple rib fractures (adjacent unifocal fractures) and flail chest (three or more adjacent bifocal rib fractures with paradoxical chest wall movement) have high mortality $(18.7 \%)$

\section{Strengths and limitations of this study}

Multiple databases were searched for studies and study selection was undertaken by two researchers, reducing the risk of error.

- Risk of bias of studies was assessed using the ROBIS tool by two researchers.

- Primary research within the reviews was mapped to identify if the reviews were based on the same primary evidence.

Reviews were included regardless of risk of bias.

due to the associated complications of acute respiratory distress syndrome, pneumonia and haemorrhage. ${ }^{1}$ Chest trauma accounts for $15 \%$ of all trauma admissions ${ }^{2}$ most commonly high-energy transfer injury as a result of a road traffic accidents $(57.01 \%)$ but also from low energy falls $(22.96 \%) .{ }^{1}$ Flail chest in particular has a high mortality rate as chest wall disruption causes an increase in the work of breathing for patients who are often in significant pain.

Current treatment options for severe chest injury are mainly supportive, including multimodal analgesia and anaesthesia, as well as non-invasive and invasive ventilation. ${ }^{3}$ Surgical fixation is thought to be beneficial to patients with respiratory failure, ${ }^{4}$ intractable pain ${ }^{5}$ or if failing to wean from invasive ventilation secondary to chest trauma. ${ }^{67}$ Fixation has potential to restore chest wall biomechanics and reduce the complications associated with poor ventilation and secretion clearance. ${ }^{7}$ Due to the rapidly, although heterogeneous, growing evidence base from multiple systematic reviews it is essential to synthesise evidence for this intervention to ascertain safety and efficacy.

This report is part of a wider systematic review to (1) identify and synthesise the evidence of the effectiveness of surgical rib fracture fixation, (2) evaluate the evidence for indications and timing of fixation and (3) 
identify the outcomes reported in the literature. Systematic reviews and primary studies were eligible for inclusion. This paper maps and synthesises this evidence from systematic reviews assessing the effectiveness of fixation of rib fractures.

\section{METHODS}

The review was undertaken systematically using the methods described by the Centre for Reviews and Dissemination. $^{8}$

\section{Eligibility criteria}

Population

Adults (over 18years) who have sustained one or more rib fractures following blunt chest trauma, with or without pulmonary contusion were eligible. Single rib fracture, multiple rib fractures and flail chest injuries were included but treated as separate injuries and therefore reported and analysed separately. Patients with penetrating injuries were excluded. Studies of mixed populations with penetrating and non-penetrating injuries were included only if data were presented separately for the two groups. Surgery for chronic non-union was excluded.

\section{Intervention}

Any method of internal surgical fixation such as plate or strut fixation; metal or synthetic material including intramedullary splints and suture fixation were eligible for inclusion.

\section{Comparator}

External surgical fixation (traction methods, splints and Hoffman style pin and bar fixation) and non-surgical management (such as supportive ventilation, epidural and regional anaesthesia).

\section{Outcomes}

All outcomes were eligible (eg, mortality, pain and pneumonia). The primary outcome of interest was duration of mechanical ventilation due to the close relationship with mortality and morbidity of ventilator associated complications.

\section{Study design}

Inclusion

Systematic reviews were included if they specified a search strategy in at least one literature database and included primary research. No restrictions were placed on the study design of the primary studies.

\section{Exclusion}

Literature reviews that did not have a defined research question, search strategy or defined process of selecting articles.

\section{Search strategy}

MEDLINE including PreMEDLINE, EMBASE, Cochrane Database of Systematic Reviews and Science Citation
Index. Clinical guidance, policy documents and relevant databases such as National Institute for Health and Care Excellence (NICE) Evidence, the UK Department of Health policy content, National Clinical Guideline Centre and Scottish Intercollegiate Guidelines Network were searched on 14 December 2016 and updated on 13 March 2017. The Conference Proceedings Citation Index was also searched for unpublished literature.

The start date for the MEDLINE searches was 1976 as that was the year that Advance Trauma Life Support was introduced internationally, incorporating new methods of resuscitation which have significantly improved outcomes.

The search strategy, developed for MEDLINE, is provided in online supplementary file 1 and was adapted to run appropriately on other databases. To identify relevant further reviews reference lists of included studies were assessed for eligibility.

\section{Selection}

Searches were downloaded into Endnote X7 (Clarivate Analytics, V.7.1 release date 2 April 2014) and de-duplicated. Two researchers (HI and EC) independently screened titles and abstracts. Any paper classified as potentially eligible by either reviewer was ordered as a full text and independently screened by both reviewers. It was originally planned to have second screening of only $50 \%$ but resources allowed for full duplicate screening. A third researcher reviewed disagreements $(\mathrm{CM})$ where a consensus could not be reached between the researchers.

\section{Data extraction}

Extracted data included study characteristics, patient characteristics, intervention, comparator, outcome measures, duration of follow-up, effect estimates, SE and CIs as available.

One researcher completed data extraction (HI); a second researcher cross-checked 50\% (EC). Discrepancies were cross-checked by both researchers at a second review and a consensus reached.

\section{Risk of bias}

Quality assessment with the ROBIS tool ${ }^{9}$ was undertaken by one researcher (HI) and checked by a second (CM). Discrepancies were resolved by discussion.

\section{Data synthesis}

All types of internal surgical fixation were synthesised as one group. Flail chest and multiple rib fractures are considered different injuries and were synthesised separately for each outcome extracted. Each outcome was narratively synthesised including number of reviews using the outcome and effect estimates with 95\% CIs from the source review. Important numerical data was presented in tables for all outcomes measured. All outcomes that were reported in the reviews were included in the report to avoid reporting bias. ${ }^{10}$ Although not fully applicable, reporting was in accordance as much as possible with the 
Preferred Reporting Items for Systematic Reviews and Meta-Analyses statement. ${ }^{11}$

\section{Protocol deviations}

The registered protocol encompasses a larger body of work which includes synthesis of primary research for effectiveness, indications for surgery, timing of surgery and mapping of outcome measures. Only the synthesis of systematic reviews is reported here. Although all outcomes were extracted and presented in tables only those that were measured in two or more studies were narratively synthesised.

\section{Patient involvement}

Patients were not involved in the preparation or conduct of this review.

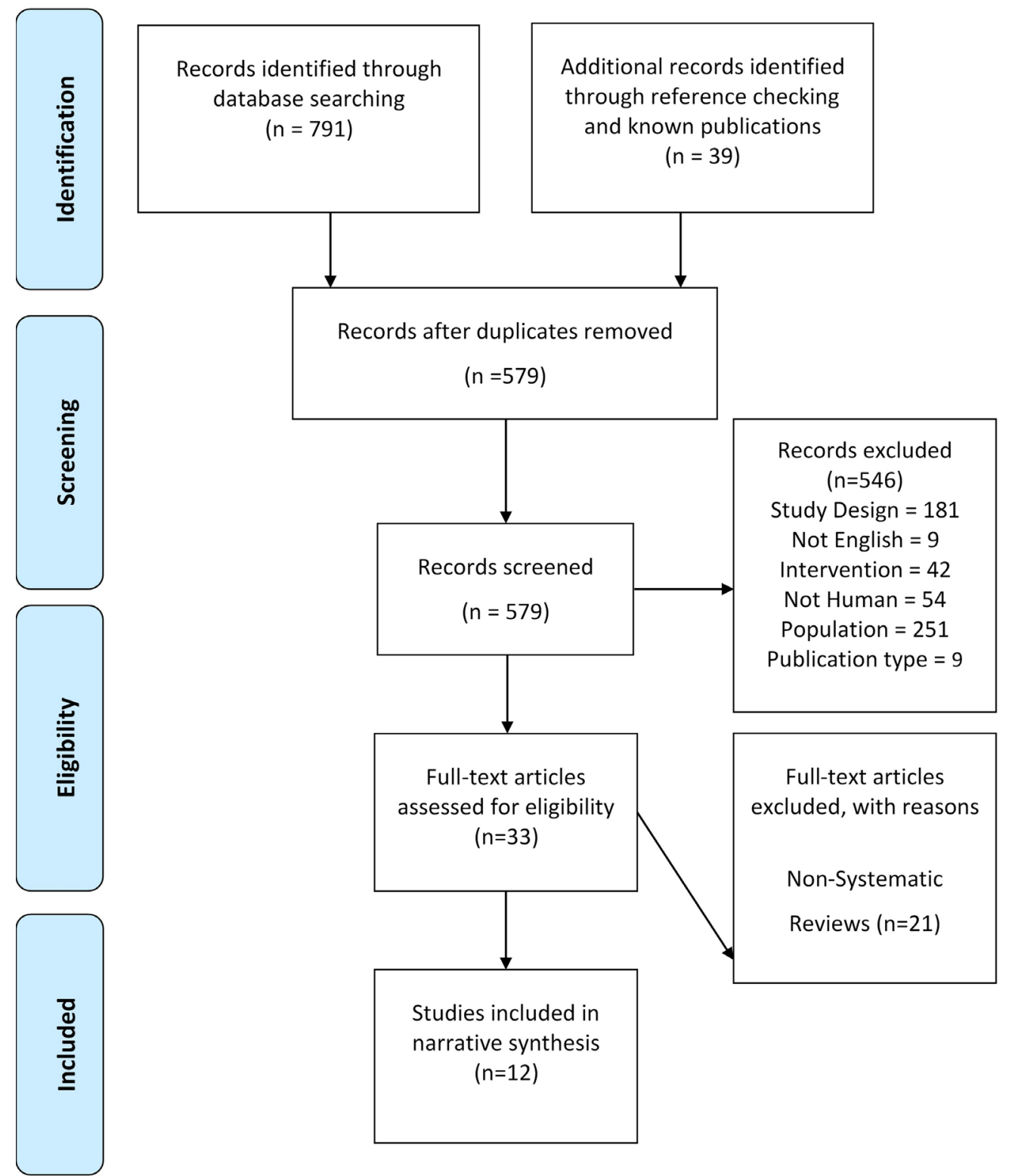

\section{RESULTS}

Electronic searches identified 791 records; an additional 39 records were collected following reference checking. The full text screening identified 12 systematic reviews eligible for inclusion, there were 21 papers excluded because they were not classified as systematic reviews (figure 1). See online supplementary file 2 lists the excluded studies.

\section{Review characteristics}

Eleven systematic reviews and one rapid evidence synthesis, ${ }^{12}$ published between 2010 and June 2016, met the inclusion criteria. Table 1 provides a summary of review characteristics. Three of the reviews ${ }^{13-15}$ were presented as best evidence topics ${ }^{16}$

Nine reviews ${ }^{12} 1315$ 17-22 evaluated the effectiveness of internal surgical fixation in patients with flail chest, two

Figure 1 Preferred Reporting Items for Systematic Reviews and Meta-Analyses flow diagram. 


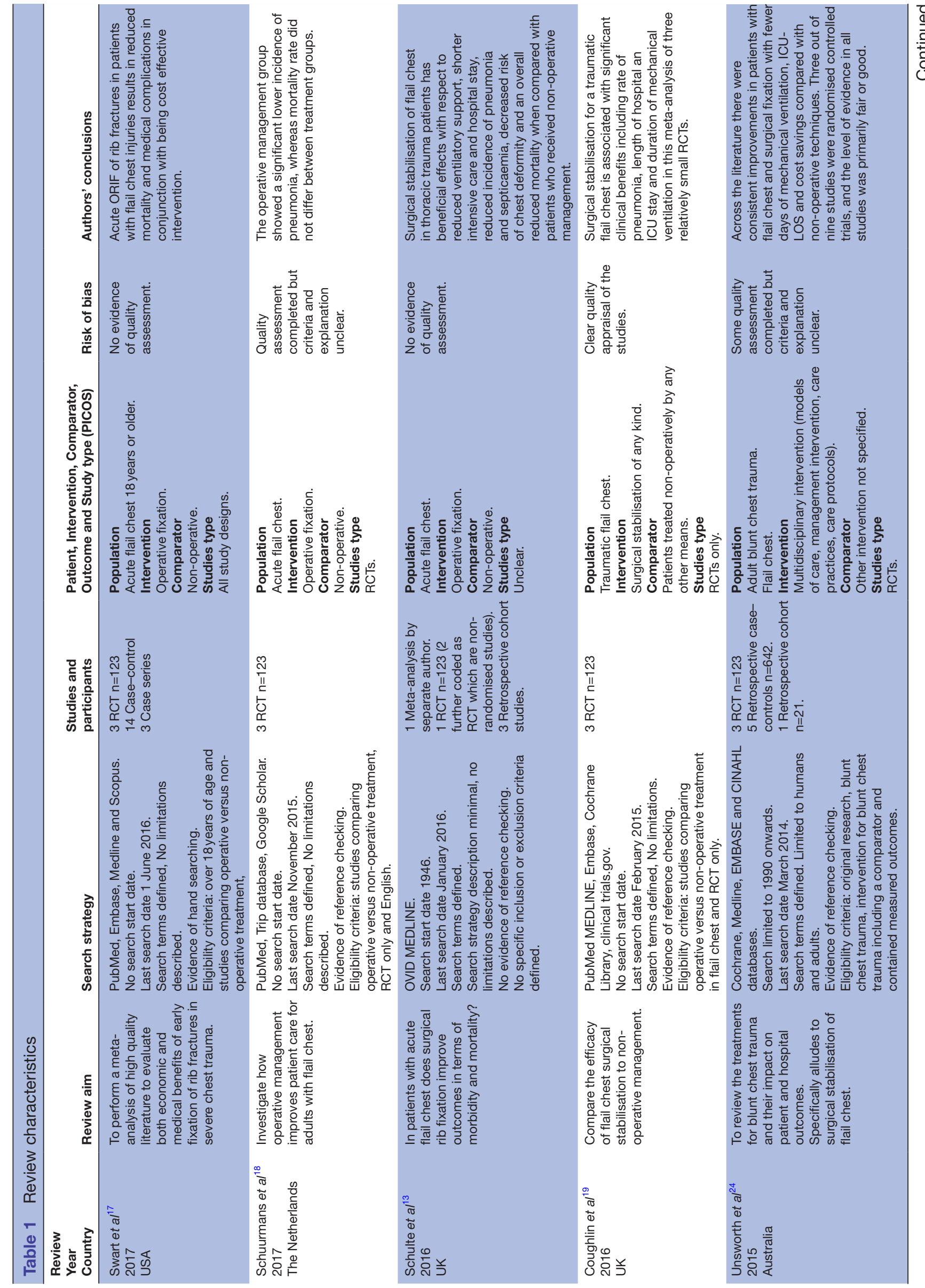




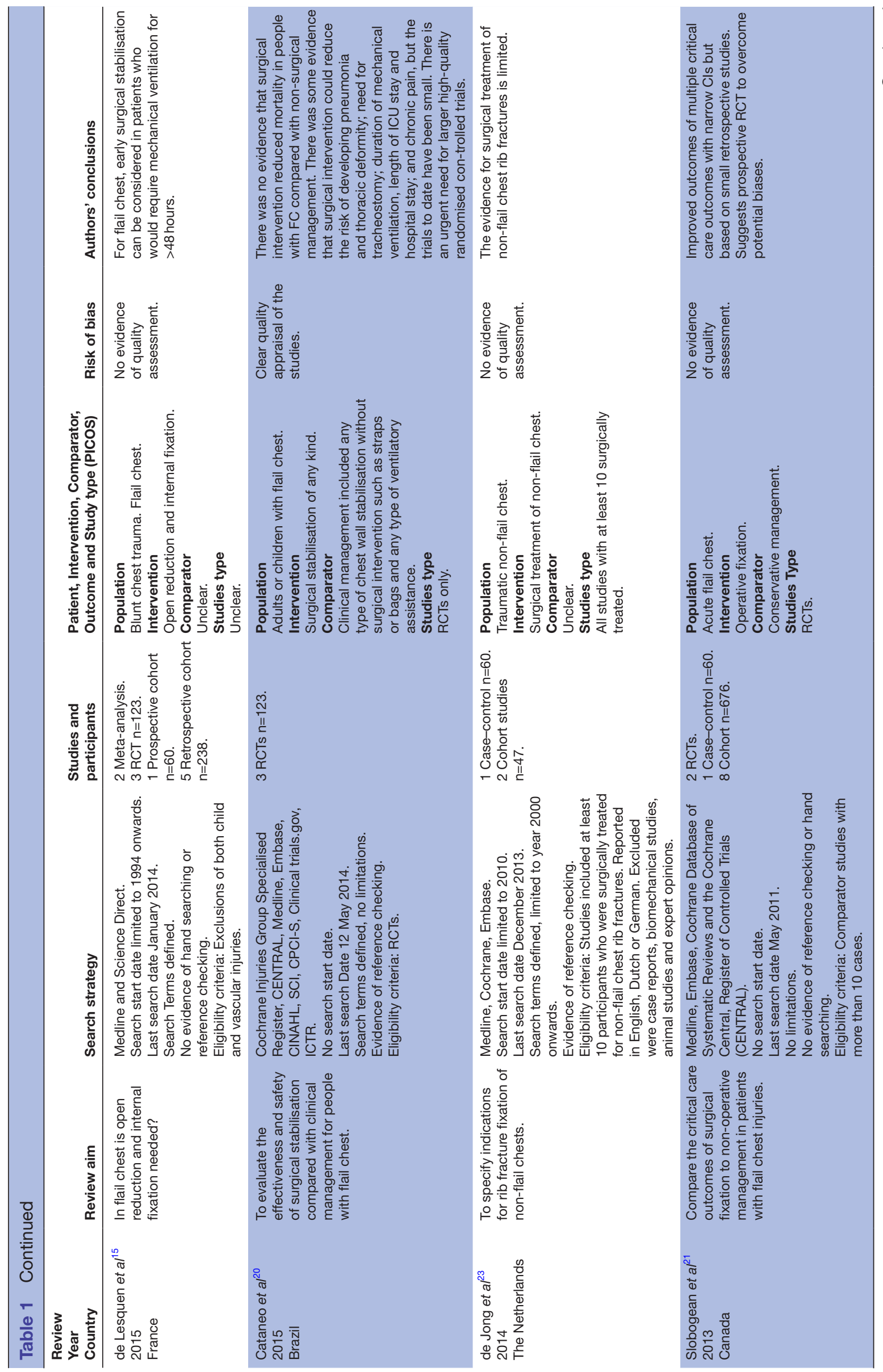




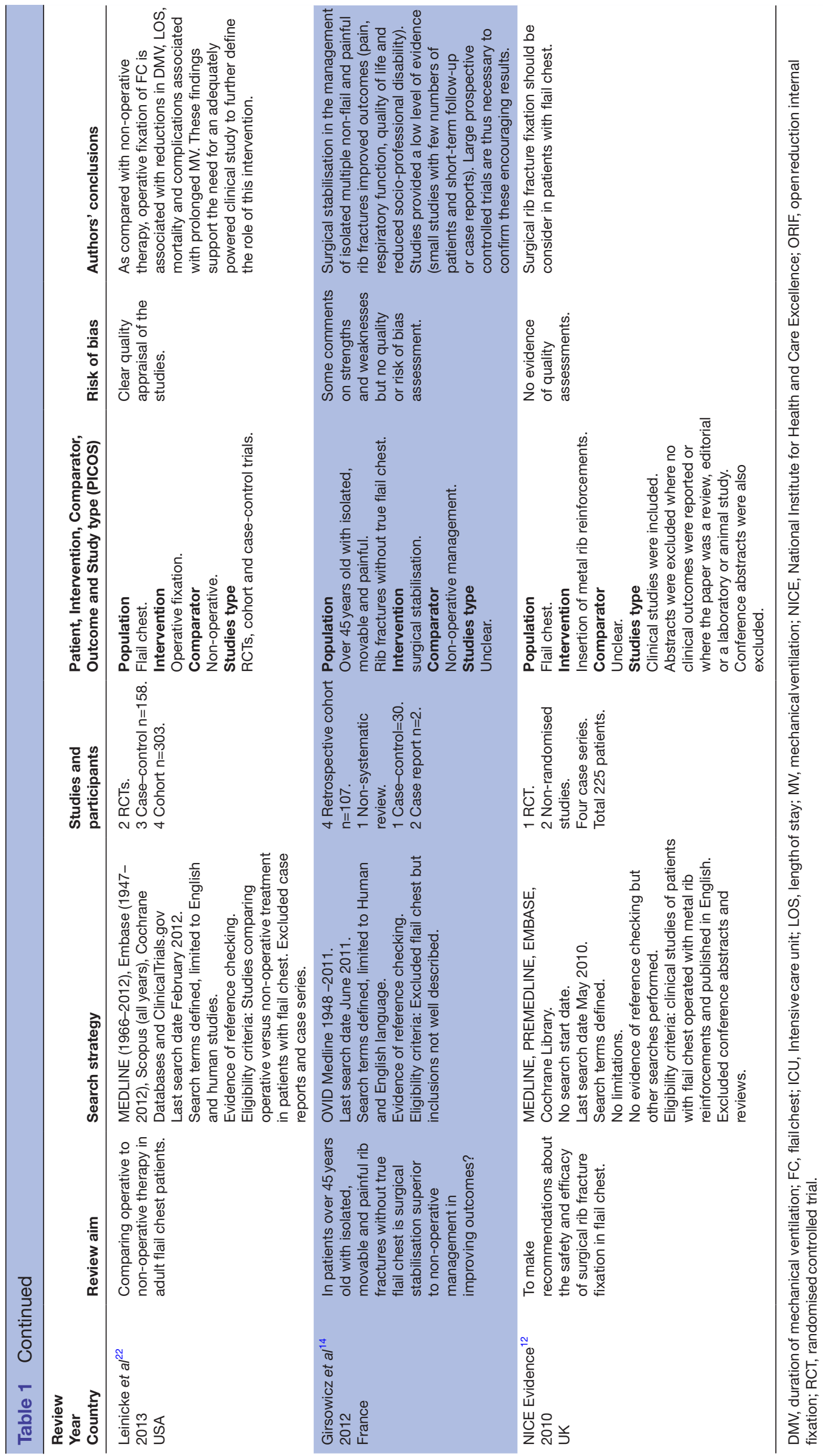


included patients with multiple rib fractures ${ }^{142}$ and one included all rib fractures but only reported outcomes for flail chest. ${ }^{24}$

Three reviews ${ }^{18-20}$ included only RCTs and eight included other study designs ${ }^{12-15} 17$ 21-23 $^{21}$ (two systematic reviews, 19 non-randomised studies, 11 case series and two case reports) (table 2). As would be expected, there was overlap across the reviews in the included primary studies. The total number of patients who had internal fixation in primary studies (excluding duplicate studies) was 1036, and there were 1187 controls.

The rapid evidence synthesis by $\mathrm{NICE}^{12}$ was the first review published in 2010, consisting of seven primary studies including one RCT published in $2001 .{ }^{25}$ Cataneo et $a l^{20}$ was the first meta-analysis published (in 2015) and included three RCTs. ${ }^{25-27}$ Two further systematic reviews published since then ${ }^{18} 19$ identified the same three RCTs and repeated the same meta-analyses for the same review question.

\section{Risk of bias}

Seven reviews rated as low risk of bias, ${ }^{12} 15$ 18-22 three as unclear $^{141723}$ and two as high. ${ }^{13}$ (table 3)The high risk of bias rating was due to lack of detail in the search strategy, no attempts to minimise errors of data extraction and no quality assessment of included studies.

The only review for which a protocol was identified was the Cochrane review undertaken by Cataneo $e t a l^{20}$

\section{Outcome evaluation}

All reviews undertook a narrative synthesis with six also including a meta-analysis. ${ }^{17-22}$ Table 4 summarises the meta-analyses for flail chest, table 5 summarises the narrative syntheses for flail chest and table 6 the narrative syntheses for multiple rib fractures. Across all the reviews, 18 outcomes were reported and 11 outcomes were reported by more than one review.

\section{Primary outcome: length of mechanical ventilation (days)}

\section{Flail chest}

Ten systematic reviews reported length of mechanical ventilation; six undertook a meta-analysis ${ }^{17-22}$ four ${ }^{17-20}$ of which included the same three RCTs. ${ }^{25-27}$

There was substantial variation across the reviews in the pooled estimates for this outcome, related to pooling different sets of studies. The largest reduction in duration of mechanical ventilation when surgery is compared with no surgery was reported by Slobogean et $a l^{21}$ pooling two RCTs ${ }^{25} 26$ and six non-randomised studies ${ }^{28-33}$ (mean difference $[\mathrm{MD}]-7.5$ days, $95 \% \mathrm{CI}-9.9$ to -5.5 ) (table 4 ). The MD was 3 days greater than the pooled estimates from Leinicke $e t a l^{22}(-4.52$ days, $95 \%$ CI -5.54 to -3.50$)$ and Swart et $a l^{17}$ (-4.57 days, SD 0.59).

There were differences in the data reported across the four meta-analyses ${ }^{17-20}$ that included the same three RCTs. Schuurmans et $a l^{18}$ extracted median duration from the Marasco et al $\mathrm{RCT},{ }^{27}$ producing an estimate MD -6.53 days, $95 \%$ CI -11.88 to -1.18 . In contrast, Coughlin et $a l^{19}$ Cataneo et $a l^{20}$ and Swart et $a l^{17}$ report the total mean time on mechanical ventilation which they state was obtained directly from the authors producing an estimate MD -6.30 days, $95 \%$ CI -12.16 to -0.43 .

Variations also arose in relation to the extraction of data from the RCT by Granetzny et $a l^{26}$ who did not report SDs for mechanical ventilation. Slightly different $\mathrm{SD}$ values are found in all six meta-analyse ${ }^{17-22}$ which may have arisen from different methods of imputation and all give slightly different estimates.

Substantial heterogeneity was seen in all meta-analyses reporting this outcome $18192122\left(\mathrm{I}^{2}=48 \%\right.$ to $\left.95 \%\right)$. Only one study ${ }^{20}$ did not pool due to heterogeneity.

Narrative synthesis from two reviews concluded that surgery reduces the length of mechanical ventilation compared with no surgery ${ }^{15}$ (table 5).

\section{Multiple rib fractures}

Two reviews ${ }^{14}{ }^{23}$ included one primary study ${ }^{33}$ that had matched non-operative controls ${ }^{33}$ (non-operative treatment not described) and reported a statistically significant reduction in postoperative ventilator days $(\mathrm{p}=0.02)$ in favour of the fixation group (table 6 ) but no statistically significant difference in total ventilator days $(\mathrm{p}=0.12)$.

\section{Mortality}

Flail chest

Seven reviews reported mortality; six undertook a meta-analysis. ${ }^{15} 1^{17-22}$ Three reviews ${ }^{18-20}$ which pooled the same three RCTs ${ }^{25-27}$ showed a non-statistically significant reduction in mortality with surgery compared with no surgery (risk ratio [RR] $0.56,95 \%$ CI [0.13 to 2.42$]^{1820}$ and RR $0.57,95 \%$ CI [0.13 to 2.52$]^{19}$ [table 4$]$ ).

Three reviews pooled randomised and non-randomised studies. ${ }^{17} 2122$ Estimates were RR 0.19 , 95\% CI 0.13 to $0.26^{21}$; (RR $0.43,95 \%$ CI 0.28 to $0.69^{22}$ and RR 0.44 , SD $0.09 .{ }^{17}$ Overall, statistical heterogeneity was low $\left(\mathrm{I}^{2}=0 \%\right)$ for this outcome in all studies that presented this data. ${ }^{17-22}$

\section{Multiple rib fractures}

Mortality was not assessed by de Jong et $a l^{23}$ or Girsowicz et al. ${ }^{14}$

\section{Length of intensive care unit stay (days)}

Flail chest

Eight reviews ${ }^{12} 15$ 17-22 assessed length of intensive care unit (ICU) stay; six undertook a meta-analysis. ${ }^{17-22}$ Pooled estimates ranged from -3.25 days (SD 1.29$)^{17}$ to -6.46 days, $95 \% \mathrm{CI}-9.73$ to $-3.19^{19}$ and were all in favour of surgical fixation compared with a variety of comparators (table 4). The range in pooled estimates may be partly explained by the pooling of different sets of studies. However, differences occurred as some pooled median length of ICU stay and others pooled the mean. Furthermore, some used postoperative time spent in ICU and others the total time spent in ICU. ${ }^{17-19}$

Variation also arose across reviews in the data extracted from a trial that did not report SDs in the primary publication. ${ }^{26}$ Values were imputed or the raw data obtained 


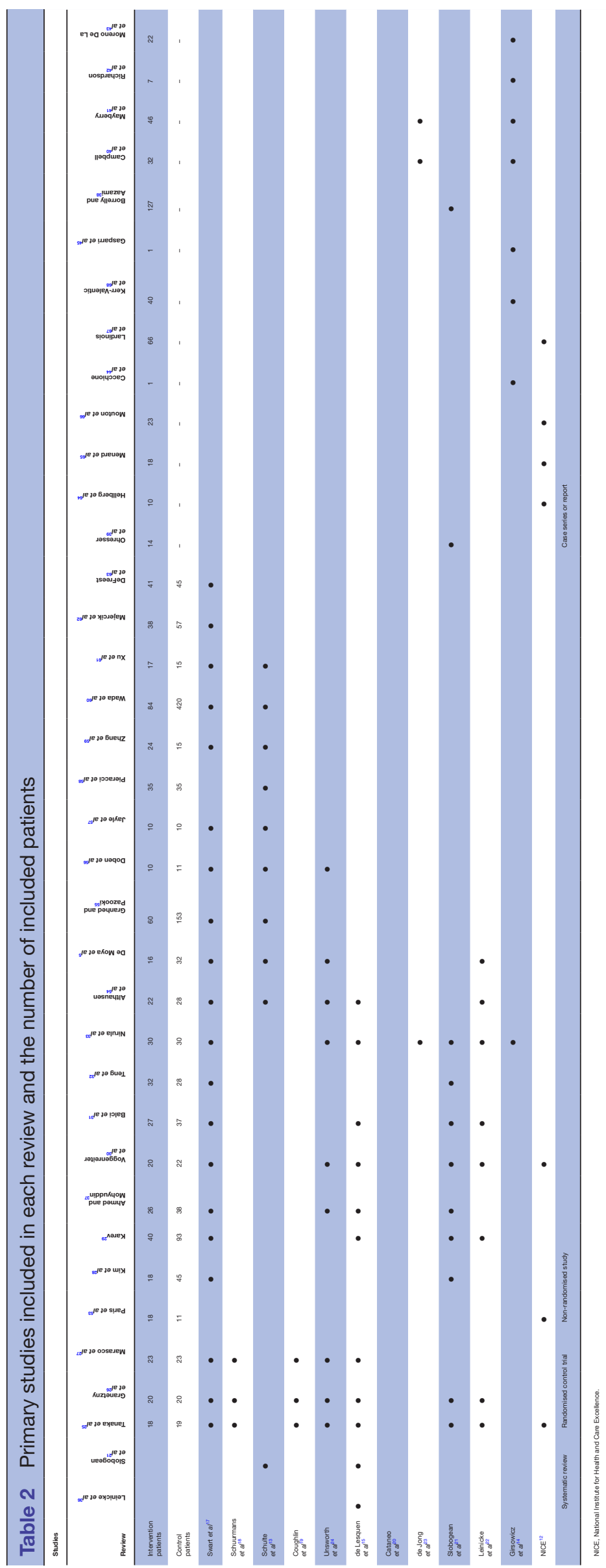

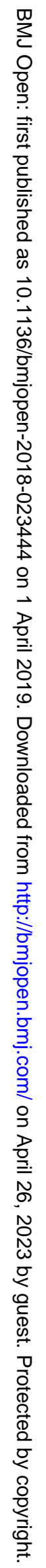


Table 3 Risk of bias using ROBIS tool

\begin{tabular}{|c|c|c|c|c|c|}
\hline Studies & $\begin{array}{l}\text { Study eligibility } \\
\text { criteria }\end{array}$ & $\begin{array}{l}\text { Identification and } \\
\text { selection of studies }\end{array}$ & $\begin{array}{l}\text { Data collection } \\
\text { and study } \\
\text { appraisal }\end{array}$ & $\begin{array}{l}\text { Synthesis and } \\
\text { findings }\end{array}$ & $\begin{array}{l}\text { Risk of bias in } \\
\text { the review }\end{array}$ \\
\hline Swart et al ${ }^{17}$ & Low & Unclear & High & High & Unclear \\
\hline Schuurmans et al ${ }^{18}$ & Low & Unclear & High & Low & Low \\
\hline Schulte et $\mathrm{al}^{13}$ & High & High & High & High & High \\
\hline Coughlin et $a l^{19}$ & Low & Low & Low & Low & Low \\
\hline Unsworth et $a^{24}$ & Low & Low & Unclear & Unclear & High \\
\hline de Lesquen et $a l^{15}$ & Unclear & High & Unclear & Unclear & Low \\
\hline Cataneo et $\mathrm{al}^{20}$ & Low & Low & Low & Low & Low \\
\hline de Jong et $a l^{23}$ & High & Unclear & High & High & Unclear \\
\hline Slobogean et al ${ }^{21}$ & Low & Low & High & Low & Low \\
\hline Leinicke et $a l^{22}$ & Low & Low & Low & Low & Low \\
\hline Girsowicz et al ${ }^{14}$ & High & High & High & High & Unclear \\
\hline $\mathrm{NICE}^{12}$ & Low & Unclear & Unclear & Low & Low \\
\hline
\end{tabular}

NICE, National Institute for Health and Care Excellence.

from the authors resulting in SD values ranging from 0.7 to 4.4 and 2.2 to 7.3 in the operative and non-operative groups respectively. There was also a substantial difference in the effect estimate for this trial. ${ }^{26}$ In one review, ${ }^{22}$ the effect estimate of -10 days, $95 \%$ CI -15.41 to -4.59 , was 5 days greater than the estimate used from the same trial in other reviews. It is the same as the as length of mechanical ventilation effect estimate reported in the same study ${ }^{26}$ so is possibly a transcription error.

Statistical heterogeneity ranged from substantial to none $^{34}\left(\mathrm{I}^{2}=74.9 \%,{ }^{22} 40 \%,{ }^{18} 35 \%{ }^{19}\right.$ and $0.1 \%{ }^{21}$ The narrative syntheses concluded that in patients with flail chest undergoing surgical fixation length of ICU stay was reduced compared with non-operative management. ${ }^{1524}$

\section{Multiple rib fractures}

A single review ${ }^{14}$ included one non-randomised study reporting no statistically significant difference in ICU days $(p=0.51)$, the MD and $95 \%$ CI was not reported. ${ }^{33}$

\section{Length of hospital stay (days)}

Flail chest

Nine reviews ${ }^{12} 15$ 17-22 24 reported length of hospital stay, six undertook a meta-analysis. ${ }^{17-22}$ Two reviews ${ }^{1720}$ pooled the same two trials ${ }^{2526}$ and found a significantly shorter hospital length of stay in favour of surgery compared with non-operative management (MD -11.39 days $95 \% \mathrm{CI}$ -12.39 to -10.38$)$. When non-randomised studies were included in the meta-analysis the pooled effects were smaller -3.83 days, $95 \%$ CI -7.12 to $-0.54^{22} ;-4$ days, $95 \% \mathrm{CI}-7.4$ to $-0.7^{21}$ and -4.48 days, SD $1.9^{17}$ in favour of fixation (table 4).

Heterogeneity ranged from low $\left(\mathrm{I}^{2}=0,{ }^{18}{ }^{19}\right.$ meta-analyses of RCTs only) to moderate or substantial $\left(\mathrm{I}^{2}=89 \%,{ }^{17}\right.$ $\mathrm{I}^{2}=68.9 \%{ }^{22}$ and $\left.\mathrm{I}^{2}=33 \%\right) .{ }^{21}$

\section{Multiple rib fractures}

Two systematic reviews ${ }^{14}{ }^{23}$ (table 6) included a single non-randomised study ${ }^{33}$ reporting no statistically significant difference in hospital stay with surgery (mean 18.8 days [SD 1.8]) compared with the non-operative management (21.1 days [SD 3.9]), $\mathrm{p}=0.59$ ).

\section{Pneumonia}

Flail chest

Ten reviews, ${ }^{12} 15$ 17-22 35 reported the risk of developing pneumonia, six undertook a meta-analysis. ${ }^{13}{ }^{17-22} 24$ Three RCTs $^{25-27}$ were pooled in two of the reviews ${ }^{15} 17$ and they found a RR of $0.36,95 \%$ CI 0.15 to 0.85 , in favour of fixation compared with non-operative management. When non-randomised studies were combined the RR ranged from $0.31,95 \% \mathrm{CI} 0.21$ to $0.41^{21}$ to $0.45,95 \% \mathrm{CI} 0.29$ to $0.70^{36}$ in favour of fixation (table 4). Substantial heterogeneity was seen in meta-analyses for this outcome ${ }^{18-20}$ that included the three $\mathrm{RCTs}^{25-27}\left(\mathrm{I}^{2}=66 \%\right.$ to $\left.74 \%\right)$. In the reviews that pooled the RCTs alongside the non-randomised studies ${ }^{21} 22$ there were lower levels of heterogeneity $\left(\mathrm{I}^{2}=4 \%\right.$ and $\mathrm{I}^{2}=31 \%$, respectively).

Two narrative syntheses report that among patients with flail chest, risk of pneumonia was reduced in the surgery group compared with the no surgery group (table 5). 1524

\section{Tracheostomy}

Flail chest

Five reviews reported a meta-analysis for tracheostomy. ${ }^{171820-22}$ Pooled RRs ranged from $0.25,95 \%$ CI 0.13 to 0.47 to $0.40,95 \% \mathrm{CI} 0.2$ to 0.7 (table 4 ). Moderate and substantial heterogeneity was seen in two reviews $\left(\mathrm{I}^{2}=42 \%,{ }^{17} \mathrm{I}^{2}=64 \%\right),{ }^{20}$ low in two reviews ${ }^{21} 22\left(\mathrm{I}^{2}=0 \%\right)$ and one did not report heterogeneity. ${ }^{18}$ 


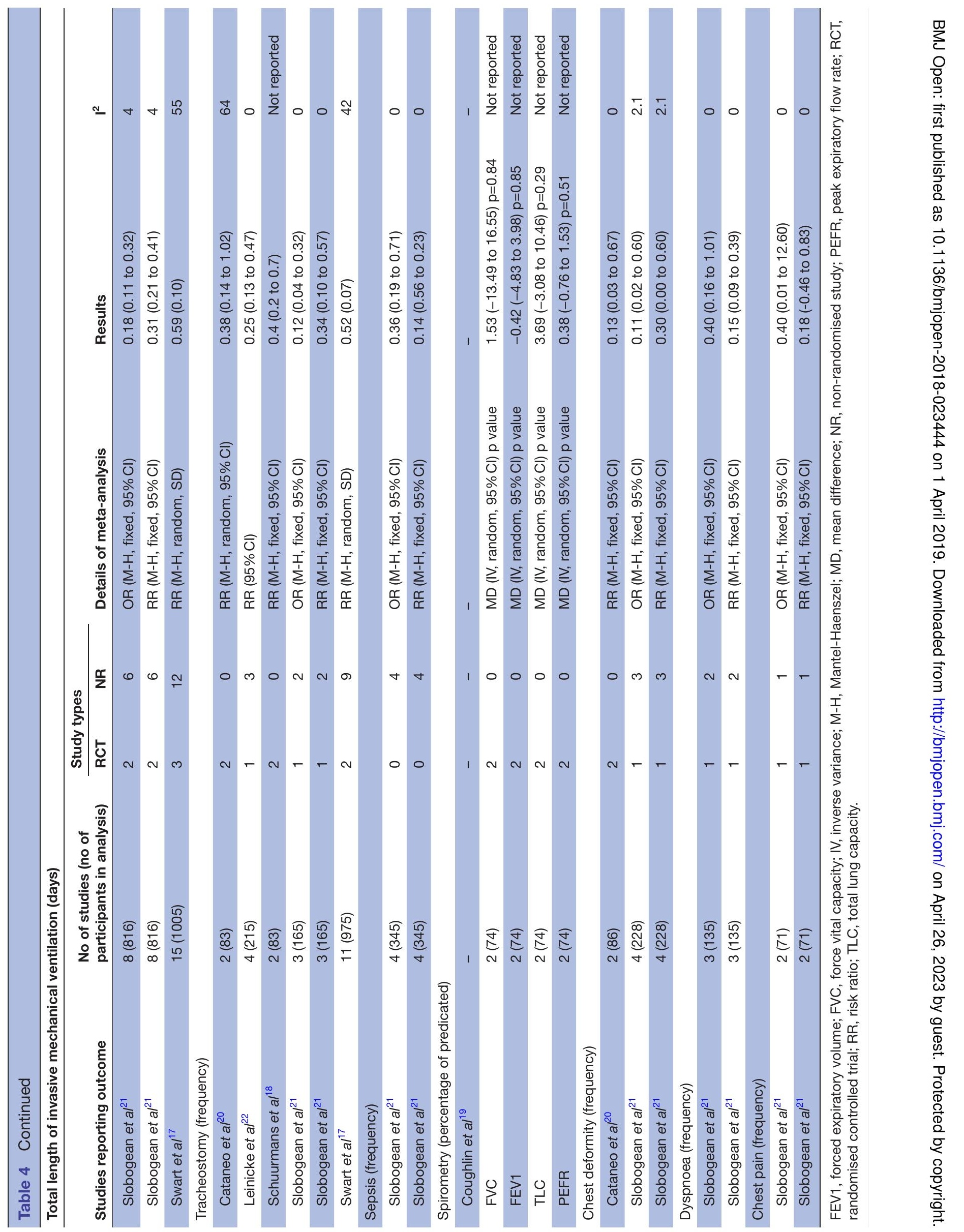




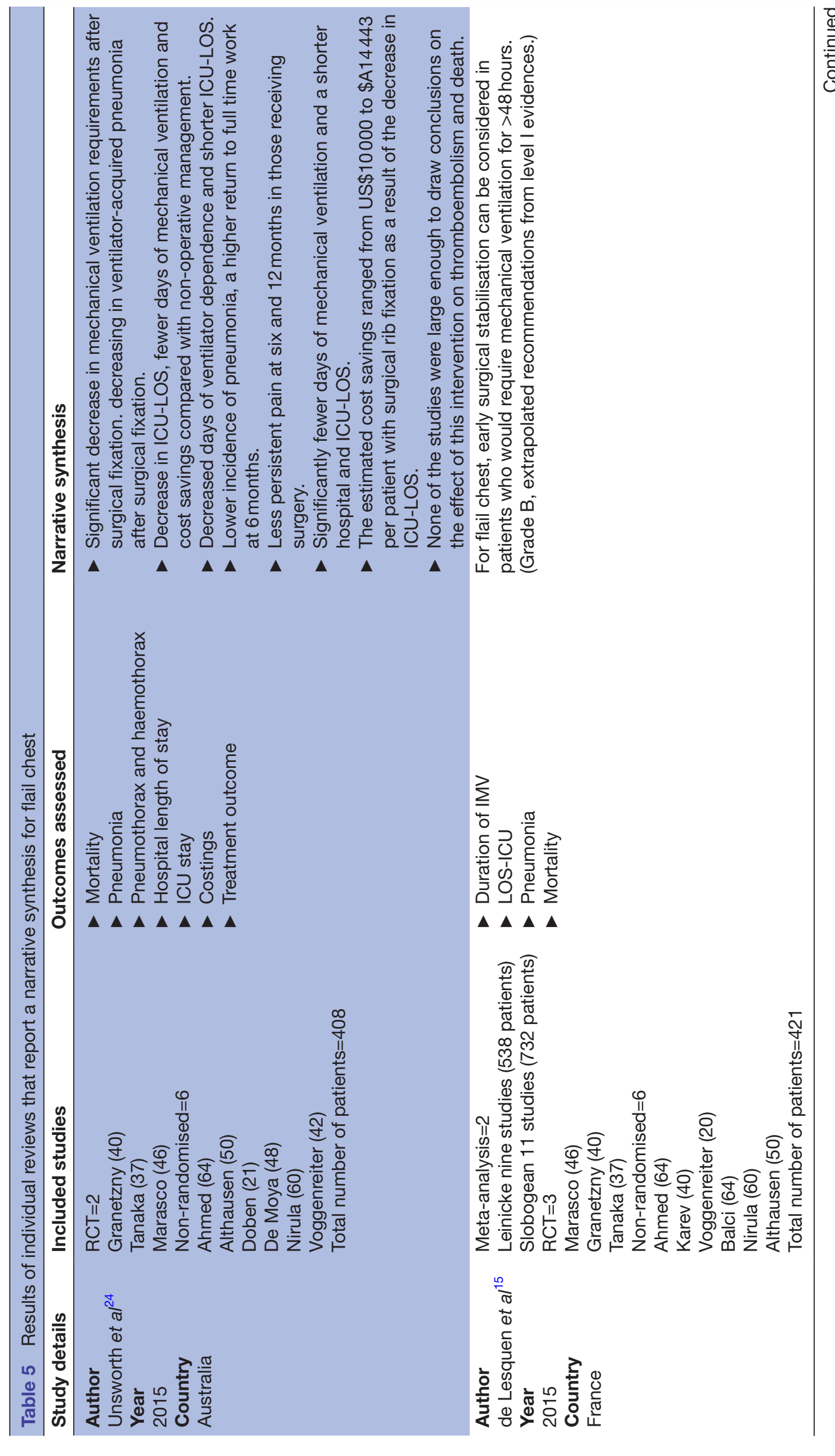




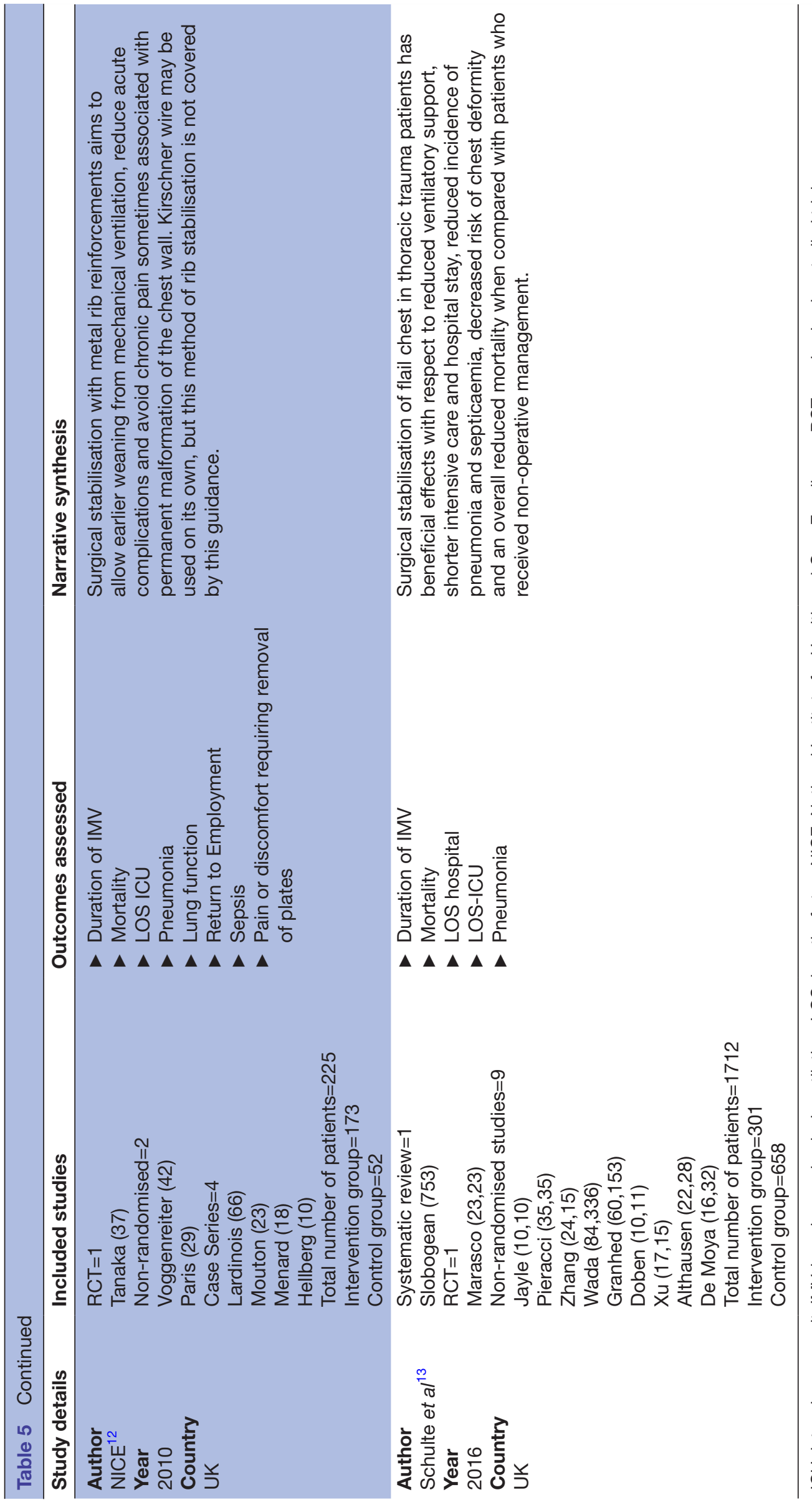


Table 6 Results of individual reviews that report a narrative synthesis for multiple rib fractures

\begin{tabular}{|c|c|c|c|}
\hline Study details & Included studies & Outcomes assessed & Narrative synthesis \\
\hline $\begin{array}{l}\text { Author } \\
\text { de Jong et } \mathrm{al}^{23} \\
\text { Year } \\
2014 \\
\text { Country } \\
\text { The Netherlands }\end{array}$ & $\begin{array}{l}\mathrm{RCT}=0 \\
\text { Non-randomised }=1 \\
\text { Nirula }(60) \\
\text { Case series }=2 \\
\text { Campbell }(32) \\
\text { Mayberry }(46,15 \text { non-flail) } \\
\text { Total number of patients }=138 \\
\text { Intervention group }=108 \\
\text { Control group }=30\end{array}$ & $\begin{array}{l}\text { LOS hospital } \\
\text { Duration of IMV } \\
\text { Time of operation } \\
\text { Chronic pain }\end{array}$ & $\begin{array}{l}\text { Only Nirula et }\left.a\right|^{33} \text { concluded that rib } \\
\text { fracture fixation showed a trend toward } \\
\text { fewer total ventilator days. Mayberry et } \\
\left.a\right|^{41} \text { investigated the quality of life after rib } \\
\text { fixation, and they concluded that there was } \\
\text { low long-term morbidity and pain. Campbell } \\
\text { et } a l^{40} \text { demonstrated low levels of pain and } \\
\text { satisfactory rehabilitation. }\end{array}$ \\
\hline $\begin{array}{l}\text { Author } \\
\text { Girsowicz et al }{ }^{14} \\
\text { Year } \\
2012 \\
\text { Country } \\
\text { France }\end{array}$ & $\begin{array}{l}\text { Non-systematic review=1 } \\
\text { Nirula and Mayberry } \\
\text { Case Comparator=1 } \\
\text { Nirula }(30,30) \\
\text { Case Series=4 } \\
\text { Mayberry }(46) \\
\text { Richardson }(7) \\
\text { Barajas }(22) \\
\text { Campbell }(32) \\
\text { Case report=3 } \\
\text { Gasparri }(1) \\
\text { Cacchione }(1) \\
\text { Kerr-Valentic }(1) \\
\text { Total number of patients=169 } \\
\text { Intervention group=139 } \\
\text { Control group=30 }\end{array}$ & $\begin{array}{l}\text { Pain } \\
\text { Disability } \\
\text { Respiratory function } \\
\text { Number of days lost } \\
\text { from work }\end{array}$ & $\begin{array}{l}\text { In general, of the nine studies presented, } \\
\text { all indicated that surgical stabilisation in the } \\
\text { management of isolated multiple non-flail } \\
\text { and painful rib fractures improved outcomes. } \\
\text { Indeed, the interest and benefit was shown } \\
\text { not only in terms of pain and respiratory } \\
\text { function but also in improved quality of life } \\
\text { and reduced socio-professional disability. } \\
\text { Hence, the current evidence shows surgical } \\
\text { stabilisation to be safe and effective in } \\
\text { alleviating post-operative pain and improving } \\
\text { patient recovery, thus enhancing the outcome } \\
\text { of the procedure. However, retrieved } \\
\text { studies provided a low level of evidence } \\
\text { (small studies with few numbers of patients } \\
\text { and short-term follow-up or case reports). } \\
\text { Large prospective controlled trials are thus } \\
\text { necessary to confirm these encouraging } \\
\text { results. }\end{array}$ \\
\hline
\end{tabular}

IMV, invasive mechanical ventilation; LOS, length of stay; RCT, randomised controlled trial.

\section{Sepsis}

Flail chest

One review, ${ }^{21}$ pooling four non-randomised studies ${ }^{28303738}$ estimated a RR of $0.14,95 \%$ CI 0.56 to 0.23 with $\mathrm{I}^{2}=0 \%$ in favour of fixation compared with non-operative management for sepsis. The estimate RR reported is not possible given the CI does not include the estimated value, 0.14. The lower interval of 0.56 could possibly be -0.56 creating a wider CI and would suggest that the author's conclusion was correct and there was a statistically significant difference in favour of fixation.

\section{Spirometry}

Flail chest

One review ${ }^{19}$ reported a meta-analysis of spirometry data which included two RCTs ${ }^{2627}$ with spirometry measured at two different time points (three and 2 months respectively). No statistically significant differences in any spirometry data were seen between surgery and no surgery (table 4).

\section{Chest deformity}

\section{Flail chest}

Two reviews reported a meta-analysis of chest deformity, ${ }^{20} 21$ both reported a statistically significant difference in favour of surgery compared with no surgery (RR
$0.30,95 \%$ CI 0.00 to $0.60, \mathrm{I}^{2}=2.1 \%$ and RR $0.13,95 \%$ CI 0.03 to $\left.0.67, \mathrm{I}^{2}=0 \%\right)$.

\section{Dyspnoea}

Flail chest

One review ${ }^{21}$ pooled an $\mathrm{RCT}^{25}$ and two non-randomised studies. $^{3739}$ for dyspnoea (RR $0.15,95 \%$ CI 0.09 to 0.39 in favour of fixation). Duration of follow-up was 1 year for two of the primary studies ${ }^{25} 39$ and unclear in the third. ${ }^{37}$ It was unclear how dyspnoea was measured or defined in the three primary studies.

\section{Chest pain}

Flail chest

Chest pain was reported in one review ${ }^{21}$ which pooled one $\mathrm{RCT}^{25}$ and one non-randomised study ${ }^{39}$ suggesting a benefit in favour of fixation (RR 0.18, CI 95\% -0.46 to $0.83)$.

\section{Other reported outcomes}

Several other outcomes were reported within the systematic reviews however no others have been pooled in a meta-analysis. A narrative synthesis was not completed on the outcomes: wound infection, pain-requiring removal of metalwork, return to work, socio-professional disability cost, pulmonary embolism, pneumothorax and haemothorax. In 
the reviews, data on these additional outcomes was minimal and presented as a narrative synthesis without presenting numerical data (tables 5 and 6 ).

\section{DISCUSSION}

Twelve systematic reviews on the effectiveness of surgery for flail chest and multiple rib fractures published between 2010 and 2016. This is the first systematic review of reviews and highlighted that there are a large number of reviews with same aims and including the same primary studies.

\section{Flail chest}

$\mathrm{Six}^{17-22}$ of the 12 systematic reviews presented meta-analyses for flail chest based on overlapping primary studies. They reported reductions in length of mechanical ventilation, length of stay, pneumonia and tracheostomy rates with surgery compared with non-surgical management and inconsistent results for mortality. Across many of the meta-analyses there was moderate to high levels of heterogeneity and variation in the effect estimates.

A single systematic review found reductions in sepsis, dyspnoea, chest deformity and chest pain with surgery compared with no surgery management. Nevertheless, as the outcome measures were not defined it is difficult to know whether the reductions are clinically significant. Reporting of adverse outcomes was infrequent across the reviews, which could reflect lack of measurement and/ or reporting of adverse events in the primary studies or the systematic reviews. Therefore, the benefits of surgery could be overestimated in light of the potential risks not being considered. Synthesising multiple meta-analyses data that include overlapping primary studies has the potential to overestimate the strength of the findings therefore it is important to be mindful of the limited evidence on which our conclusions are based. In addition, significant heterogeneity for several of the outcomes that were pooled makes drawing firm conclusions difficult.

\section{Multiple rib fractures}

Evidence in support of multiple rib fracture fixation in the absence of flail chest is limited. Two systematic reviews ${ }^{143}$ reported on one non-randomised study ${ }^{33}$ that recruited between 1996 and 2000, four case series ${ }^{4-43}$ and two case reports. ${ }^{445}$ Hence, due to limited evidence no conclusive statements on effectiveness can be drawn.

\section{Review quality}

A significant amount of effort and time is required to conduct a high quality systematic review and should only be undertaken when there is sufficient cause ${ }^{46} 47$ (eg, to incorporate the findings of a new RCT or to address an evidence gap). Eight of the systematic reviews were published within 18 months although none were registered on PROSPERO ${ }^{48}$ so it is possible the authors were unaware of each other's research. Registering reviews allows transparency of methods and also reduces research waste. ${ }^{49}$ As similar search strategies and search dates were used in each systematic review, inevitably many of the included studies were the same across reviews.

Only two of the 12 systematic reviews formally appraised the quality of the included studies, therefore 10 of the reviews were not in a position to fully consider the impact of risk of bias on their conclusions. High or unclear risk of bias within reviews have affected the conclusions drawn from this evidence synthesis. In a systematic review of 106 emergency surgery systematic reviews, a low risk of bias was found in $53.8 \%$, identifying a common problem of poor quality reviews conducted in emergency surgery. ${ }^{50}$

\section{Heterogeneity and meta-analysis errors}

The $\mathrm{I}^{2}$ value describes the percentage of total variation across studies that is due to heterogeneity rather than chance. ${ }^{51}$ Examining the meta-analyses including RCTs highlights moderate to high levels of statistical heterogeneity.

There was also clinical variation in the primary studies in terms of indications and timing of surgery and it is possible that these between study differences could be a source of the substantial heterogeneity. For example, in one $\mathrm{RCT}^{25}$ patients were randomised after 5 days of invasive ventilation, whereas another $\mathrm{RCT}^{26}$ randomised and fixed within 24 to 72 hours regardless of initial intubation state. Also, many reviews define the comparator as usual care or non-operative care but do not elaborate on what encompasses this care. Differences in how outcomes were measured may also have contributed to between study heterogeneity. It was unknown due to lack of reporting whether the outcomes were equivalent in the pooled primary studies or overall between systematic reviews.

In all systematic reviews with meta-analyses, they reported that two reviewers were involved in the data extraction to minimise errors. ${ }^{17}{ }^{19-22}$ Despite attempts to minimise errors and therefore an apparent low risk of bias, some errors (up to an MD of 10 days in the measurement of length of intensive care stay) were identified across reviews. It is worth noting that there were no significant changes in the conclusions drawn from these analyses. Although there was substantial statistical and clinical heterogeneity and lack of consideration of risk of bias in many of the reviews, conclusions tended to be similar and in the direction of benefit with fixation suggesting that further high quality RCTs investigating the effectiveness (including adverse effects) of internal surgical fixation over non-operative management are warranted.

\section{Strengths}

Multiple databases were searched for studies and study selection was undertaken by two researchers, reducing the risk of error and bias. Although only English language studies were included, some sources of unpublished studies were searched. A mapping of the studies included in the reviews was undertaken to take into account individual studies being included in multiple reviews and hence double counting studies. 


\section{Limitations}

All systematic reviews were included irrespective of their risk of bias scoring. It could be argued that several reviews were stretching the traditional definition of a systematic review however they did hold to the protocol definition with an electronic database search strategy and included primary evidence. Due to best evidence topics and rapid evidence synthesis being included it was then difficult to apply the ROBIS tool consistently. The ROBIS tool is not designed for rapid evidence synthesis and therefore this type of review showed high risk of bias as they were being assessed against a tool designed for full systematic reviews. Rapid evidence syntheses, by their nature address a trade-off between time and methodological rigour and comprehensiveness. ${ }^{52}$

\section{CONCLUSION}

The considerable duplication of work across reviews could be mitigated through protocol registration and greater attention to establishing whether a review is necessary by scoping the literature before commencing a new review. Despite this review identifying 12 systematic reviews they only included 37 unique primary studies, only three of which were RCTs. Synthesis of the reviews has shown some potential improvement in patient outcomes with flail chest after surgical intervention. However, there were differences in indications and timing of interventions in the primary studies and moderate to high levels of heterogeneity across reviews. For future review updates, meta-analysis for effectiveness may need to take into account indications and timing of surgery as a subgroup analysis to address clinical heterogeneity between primary studies. Further robust evidence is required before conclusions can be drawn of the effectiveness of surgical fixation for flail chest and in particular, multiple rib fractures.

Contributors HMAl contributed to conceptualisation, methodology, investigation, formal analysis, original draft preparation. EC contributed to investigation, validation, review and editing. WE contributed to conceptualisation, review and editing. AR contributed to funding acquisition, conceptualisation, review and editing. $\mathrm{CH}$ contributed to methodology, supervision, conceptualisation, review and editing. CM contributed to methodology, investigation, validation, conceptualisation, supervision, review and editing. All authors approve the final version of the manuscript and are accountable for all aspects of the work.

Funding This review was completed as part of an MD project which was funded by an educational grant from Orthopaedic Research UK. The research was undertaken at the BOA Orthopaedic Surgery Research Centre (BOSRC) at York Trials Unit.

Competing interests AR declares receiving research grants from NIHR; research and educational grants from DePuy Ltd outside the submitted work.

Patient consent for publication Not required.

Provenance and peer review Not commissioned; externally peer reviewed.

Data sharing statement All data used for the preparation of this review are reported within the manuscript or its supplementary files.

Open access This is an open access article distributed in accordance with the Creative Commons Attribution Non Commercial (CC BY-NC 4.0) license, which permits others to distribute, remix, adapt, build upon this work non-commercially, and license their derivative works on different terms, provided the original work is properly cited, appropriate credit is given, any changes made indicated, and the use is non-commercial. See: http://creativecommons.org/licenses/by-nc/4.0/.

\section{REFERENCES}

1. Veysi VT, Nikolaou VS, Paliobeis C, et al. Prevalence of chest trauma associated injuries and mortality: a level I trauma centre experience. Int Orthop 2009;33:1425-33.

2. American College of Surgeons. In: Chang MC, ed. NTDB ANNUAL REPORT 2016, 2016.

3. Brasel KJ, Moore EE, Albrecht RA, et al. Western Trauma Association Critical Decisions in Trauma: Management of rib fractures. J Trauma Acute Care Surg 2017;82:200-3.

4. Vyhnánek F, Jirava D, Očadlík M, et al. [Surgical Stabilisation of Flail Chest Injury: Indications, Technique and Results]. Acta Chir Orthop Traumatol Cech 2015;82:303-7.

5. de Moya M, Bramos T, Agarwal S, et al. Pain as an indication for rib fixation: a bi-institutional pilot study. J Trauma 2011;71:1750-4.

6. Velasquez M, Ordoñez CA, Parra MW, et al. Operative versus Nonoperative Management of Multiple Rib Fractures. Am Surg 2016;82:E103-5.

7. Bhatnagar A, Mayberry J, Nirula R. Rib fracture fixation for flail chest: what is the benefit? J Am Coll Surg 2012;215:201-5.

8. Centre for Reviews and Dissemination. Systematic Reviews - CRD's guidance for undertaking reviews in health care: York Publishing Services, 2009

9. Whiting P, Savović J, Higgins JP, et al. ROBIS: A new tool to assess risk of bias in systematic reviews was developed. J Clin Epidemiol 2016;69:225-34.

10. Page MJ, McKenzie JE, Kirkham J, et al. Bias due to selective inclusion and reporting of outcomes and analyses in systematic reviews of randomised trials of healthcare interventions. Cochrane Database Syst Rev 2014;10:MR000035.

11. Moher D, Liberati A, Tetzlaff J, et al. Preferred reporting items for systematic reviews and meta-analyses: the PRISMA statement. $J$ Clin Epidemiol 2009;62:1006-12.

12. NICE. Insertion of metal rib reinforcements to stabilise a flail chest wall. Interventional procedures guidance [IPG361]. 2010.

13. Schulte K, Whitaker D, Attia R. In patients with acute flail chest does surgical rib fixation improve outcomes in terms of morbidity and mortality? Interact Cardiovasc Thorac Surg 2016;23:314-9.

14. Girsowicz E, Falcoz PE, Santelmo N, et al. Does surgical stabilization improve outcomes in patients with isolated multiple distracted and painful non-flail rib fractures? Interact Cardiovasc Thorac Surg 2012;14:312-5.

15. de Lesquen H, Avaro JP, Gust L, et al. Surgical management for the first $48 \mathrm{~h}$ following blunt chest trauma: state of the art (excluding vascular injuries). Interact Cardiovasc Thorac Surg 2015;20:399-408.

16. Khan OA, Dunning J, Parvaiz AC, et al. Towards evidence-based medicine in surgical practice: best BETs. Int J Surg 2011;9:585-8.

17. Swart E, Laratta J, Slobogean G, et al. Operative treatment of rib fractures in flail chest injuries: a meta-analysis and cost-effectiveness analysis. J Orthop Trauma 2017;31:64-70.

18. Schuurmans J, Goslings JC, Schepers T. Operative management versus non-operative management of rib fractures in flail chest injuries: a systematic review. Eur J Trauma Emerg Surg 2017;43:1.

19. Coughlin TA, Jwg N, Rollins KE, et al. Management of rib fractures in traumatic flail chest A meta-analysis of randomised control trials. Bone \& Joint Journal 2016;98B:1119-25.

20. Cataneo AJ, Cataneo DC, de Oliveira FH, et al. Surgical versus nonsurgical interventions for flail chest. Cochrane Database Syst Rev 2015;7:CD009919.

21. Slobogean GP, MacPherson CA, Sun T, et al. Surgical fixation vs nonoperative management of flail chest: a meta-analysis. J Am Coll Surg 2013;216:302-11.

22. Leinicke JA, Elmore L, Freeman BD, et al. Operative management of Rib fractures in the setting of flail chest: A systematic review and meta-analysis. Annals of Surgery 2013;258:914-21.

23. de Jong MB, Kokke MC, Hietbrink F, et al. Surgical Management of Rib Fractures: Strategies and Literature Review. Scand J Surg 2014;103:120-5.

24. Unsworth A, Curtis K, Asha SE. Treatments for blunt chest trauma and their impact on patient outcomes and health service delivery. Scand J Trauma Resusc Emerg Med 2015;23:17.

25. Tanaka H, Yukioka T, Yamaguti Y, et al. Surgical stabilization of internal pneumatic stabilization? A prospective randomized study of management of severe flail chest patients. J Trauma 2002;52:727-32.

26. Granetzny A, Abd El-Aal M, Emam E, et al. Surgical versus conservative treatment of flail chest. Evaluation of the pulmonary status. Interact Cardiovasc Thorac Surg 2005;4:583-7. 
27. Marasco SF, Davies AR, Cooper J, et al. Prospective randomized controlled trial of operative rib fixation in traumatic flail chest. J Am Coll Surg 2013;216:924-32.

28. Kim M, Brutus $P$, Christides $C$, et al. [Compared results of flail chests treatments: standard internal pneumatic stabilization, new technics of assisted ventilation, osteosynthesis (author's transl)]. J Chir 1981;118(8-9):499-503.

29. Karev DV. Operative management of the flail chest. Wiad Lek 1997:50:205-8.

30. Voggenreiter G, Neudeck F, Aufmkolk M, et al. Operative chest wall stabilization in flail chest-outcomes of patients with or without pulmonary contusion. J Am Coll Surg 1998;187:130-8.

31. Balci $A E$, Eren $S$, Cakir $O$, et al. Open fixation in flail chest: review of 64 patients. Asian Cardiovasc Thorac Ann 2004;12:11-15.

32. Teng J-P, Cheng Y-G, Da NI, et al. Outcomes of traumatic flail chest treated by operative fixation versus conservative approach. $J$ Shanghai Jiaotong Univ 2009;29:1495.

33. Nirula R, Allen B, Layman R, et al. Rib fracture stabilization in patients sustaining blunt chest injury. Am Surg 2006;72:307-9.

34. Higgins JPT, Green S. Cochrane Handbook for Systematic Reviews of Interventions. 2011.

35. Nickerson TP, Kim BD, Zielinski MD, et al. Use of a $90^{\circ}$ drill and screwdriver for rib fracture stabilization. World $J$ Surg 2015;39:789-93

36. Leinicke JA, Elmore L, Freeman BD, et al. Operative management of rib fractures in the setting of flail chest: a systematic review and meta-analysis. Ann Surg 2013;258:914-21.

37. Ahmed Z, Mohyuddin Z. Management of flail chest injury: internal fixation versus endotracheal intubation and ventilation. $J$ Thorac Cardiovasc Surg 1995;110:1676-80.

38. Borrelly J, Aazami MH. New insights into the pathophysiology of flail segment: the implications of anterior serratus muscle in parietal failure. Eur J Cardiothorac Surg 2005;28:742-9.

39. Ohresser P, Amoros JF, Leonardelli M, et al. [The functional sequelae of closed thoracic injuries (apropos of 92 cases)]. Poumon Coeur 1972;28:145-50.

40. Campbell N, Conaglen P, Martin K, et al. Surgical stabilization of rib fractures using Inion OTPS wraps-techniques and quality of life follow-up. J Trauma 2009;67:596-601.

41. Mayberry JC, Kroeker AD, Ham LB, et al. Long-term morbidity, pain, and disability after repair of severe chest wall injuries. Am Surg 2009;75:389-94.

42. Richardson JD, Franklin GA, Heffley S, et al. Operative fixation of chest wall fractures: an underused procedure? Am Surg 2007;73:591-6.

43. Moreno De La Santa Barajas P, Polo Otero MD, Delgado SánchezGracián $\mathrm{C}$, et al. [Surgical fixation of rib fractures with clips and titanium bars (STRATOS System). Preliminary experience]. Cir Esp 2010;88:180-6.

44. Cacchione RN, Richardson JD, Seligson D. Painful nonunion of multiple rib fractures managed by operative stabilization. J Trauma 2000;48:319-21.

45. Gasparri MG, Almassi GH, Haasler GB. Surgical management of multiple rib fractures. Chest 2003;124:295S-6.

46. Garner P, Hopewell S, Chandler J, et al. When and how to update systematic reviews: consensus and checklist. BMJ 2016;354:i3507.

47. Lund H, Juhl C, Christensen R. Systematic reviews and research waste. Lancet 2016;387:123-4.
48. Booth A, Clarke M, Dooley G, et al. The nuts and bolts of PROSPERO: an international prospective register of systematic reviews. Syst Rev 2012;1:2.

49. Moher D, Booth A, Stewart L. How to reduce unnecessary duplication: use PROSPERO. BJOG-Int J Obstet Gy 2014;121:784-6.

50. EMSurg Collaborators. Methodological overview of systematic reviews to establish the evidence base for emergency genera surgery. Br J Surg 2017;104:513-24.

51. Higgins JP, Thompson SG, Deeks JJ, et al. Measuring inconsistency in meta-analyses. BMJ 2003;327:557-60.

52. Featherstone RM, Dryden DM, Foisy M, et al. Advancing knowledge of rapid reviews: an analysis of results, conclusions and recommendations from published review articles examining rapid reviews. Syst Rev 2015;4:50.

53. Paris F, Tarazona V, Blasco E, et al. Surgical stabilization of traumatic flail chest. Thorax 1975;30:521-7.

54. Althausen PL, Shannon S, Watts C, et al. Early surgical stabilization of flail chest with locked plate fixation. J Orthop Trauma 2011;25:641-7

55. Granhed HP, Pazooki D. A feasibility study of 60 consecutive patients operated for unstable thoracic cage. J Trauma Manag Outcomes 2014;8:20.

56. Doben AR, Eriksson EA, Denlinger CE, et al. Surgical rib fixation for flail chest deformity improves liberation from mechanical ventilation. J Crit Care 2014;29:139-43.

57. Jayle CP, Allain G, Ingrand P, et al. Flail chest in polytraumatized patients: surgical fixation using Stracos reduces ventilator time and hospital stay. Biomed Res Int 2015;2015:1-6.

58. Pieracci FM, Lin Y, Rodil M, et al. A prospective, controlled clinical evaluation of surgical stabilization of severe rib fractures. J Trauma Acute Care Surg 2016;80:187-94.

59. Zhang $\mathrm{Y}$, Tang $\mathrm{X}$, Xie $\mathrm{H}$, et al. Comparison of surgical fixation and nonsurgical management of flail chest and pulmonary contusion. Am J Emerg Med 2015;33:937-40.

60. Wada T, Yasunaga H, Inokuchi R, et al. Effectiveness of surgical rib fixation on prolonged mechanical ventilation in patients with traumatic rib fractures: A propensity score-matched analysis. J Crit Care 2015;30:1227-31.

61. Xu JQ, Qiu PL, Yu RG, et al. Better short-term efficacy of treating severe flail chest with internal fixation surgery compared with conservative treatments. Eur J Med Res 2015;20:55

62. Majercik S, Vijayakumar S, Olsen G, et al. Surgical stabilization of severe rib fractures decreases incidence of retained hemothorax and empyema. Am J Surg 2015;210:1112-7.

63. DeFreest L, Tafen M, Bhakta A, et al. Open reduction and internal fixation of rib fractures in polytrauma patients with flail chest. $A m \mathrm{~J}$ Surg 2016;211:761-7.

64. Hellberg K, de Vivie ER, Fuchs K, et al. Stabilization of flail chest by compression osteosynthesis-experimental and clinical results. Thorac Cardiovasc Surg 1981;29:275-81.

65. Menard A, Testart J, Philippe JM, et al. Treatment of flail chest with Judet's struts. J Thorac Cardiovasc Surg 1983;86:300-5.

66. Mouton W, Lardinois D, Furrer M, et al. Long-term follow-up of patients with operative stabilisation of a flail chest. Thorac Cardiovasc Surg 1997;45:242-4.

67. Lardinois D, Krueger T, Dusmet M, et al. Pulmonary function testing after operative stabilisation of the chest wall for flail chest. Eur $J$ Cardiothorac Surg 2001;20:496-501.

68. Kerr-Valentic MA, Arthur M, Mullins RJ, et al. Rib fracture pain and disability: can we do better? J Trauma 2003;54:1058-63. 